\title{
Students' Attitudes Towards Psychological Help-Seeking
}

\author{
Mala Ramdass ${ }^{1}$, Roland Birbal ${ }^{1}$, Gail Joseph-Alleyne ${ }^{1} \&$ Cyril Harripaul $^{1}$ \\ ${ }^{1}$ Corinth Campus, University of Trinidad and Tobago, Wallerfield, Trinidad and Tobago \\ Correspondence: Mala Ramdass, $\mathrm{PhD}$, Corinth Campus, University of Trinidad and Tobago, Wallerfield, \\ Trinidad and Tobago.
}

Received: September 8, 2020

Accepted: October 11, 2020

Online Published: November 3, 2020

doi:10.20849/jed.v4i3.818

URL: https://doi.org/10.20849/jed.v4i3.818

\begin{abstract}
This study examined factors that may influence students' willingness to seek professional psychological help from the counselling services provided at a university. The study further investigated the relationship between sex, age, status of students (part-time, full-time), place of residence (urban, rural) and ethnicity and perceived barriers to seeking psychological help.

The study used a sequential explanatory mixed methods research design conducted across two phases. In Phase One, a questionnaire survey was used to measure barriers to seeking professional help from a random sample of 925 students. In the second qualitative phase, focus group interviews were conducted with students to explore in a more in-depth way reasons put forward in the survey for not seeking professional psychological help.

Statistical tests for the first phase were means, t-tests, ANOVA and Pearson Moment Product Correlation. Results showed that students viewed privacy, access, and trust issues as the most important barriers to seeking psychological help. There were also significant differences with regard to stigma, privacy and trust issues based on sex, age, year group, full-time/part-time status and ethnicity. Significant high to moderate correlations were found between all four factors. Qualitative findings supported factors examined in the first phase. However, other themes emerged such as lack of time, preference for solving one's own problems and preference for other sources of support.
\end{abstract}

Keywords: mental health, barriers, help-seeking

\section{Introduction}

There is growing concern for the mental health of university students in many countries. According to Eisenberg, Hunt, Speer and Zivin (2011) approximately 32\% of university students report having mental health problems in the United States of America. A study conducted by the American College Health Association during the period 2009 to 2015 found an increase in the number of college students who were being treated for anxiety, attention deficit hyperactivity disorder (ADHD), depression, insomnia, obsessive-compulsive disorder (OCD) and panic attacks (Oswalt, Lederer, Chestnut-Steich, Day, Halbritter \& Ortiz, 2020).

In Trinidad and Tobago, Seemungal (2018) reported that non-random estimates of depression amongst medical students at the St Augustine Campus of the University of the West Indies vary from $30 \%$ to $40 \%$ and are higher in certain subsets. The typical university student is between 18 and 25 years old, the "key age range where a lot of mental illnesses appear for the first time, like bipolar disorder or schizophrenia," says Chin Yuen Kee (as cited in Acham, 2017, p.1). She also stated that though they may be the minority, there are "students who will develop mental illnesses during their time at university."

The 2018 Report of the Joint Select Committee on Mental Health in Trinidad and Tobago indicated that an estimated $20-25 \%$ of the total population of children/adolescents suffer from a mental disorder or illness. The prevalence of mental illness amongst school students is also very high and at the time of the report there were 400 children on suicide watch, the youngest being 7 years old. In addition, the report pointed out that in a five-year study of 200 patients admitted to the St Ann's Psychiatric Hospital approximately 121 persons between the ages of 18 to 26 were admitted to medical facilities for attempted suicide (Government of Trinidad and Tobago, 2018).

While several studies have shown an increase in the number of people seeking help for psychological services, there is still a significant number who choose not to seek help for mental health problems (National Alliance of 
Mental Illness, 2014; Eisenberg et al., 2011; Vanheusden, Mulder, Van der Ende, Van Lenthe, Mackenbach \&Verhulst,2008).

\subsection{Research Problem}

This study examined factors that influence students' willingness to seek psychological help from the counseling services at the university. It further investigated differences in perceived barriers based on sex, age, residence, year group, part-time/full-time status and ethnicity. It also explored in a more in-depth way students' reasons for not seeking psychological help.

\subsection{Significance}

Previous research found that perceived barriers have a significant effect on college students' health behavior choices (Von Ah, Ebert, Ngamvitroj, Park \& Kang, 2004). A greater understanding of the barriers to accessing mental health services among university students will be useful to university health professionals to help them develop better mental health prevention and intervention programs. The results of the study can be used to improve access and delivery of counseling services. It can also provide base line data to guide initiatives to support student mental health and well-being. Additionally, it can also assist in the retention of students at the university.

\subsection{Background}

Trinidad and Tobago is a twin-island state that is located in the Caribbean. It is a post-colonial society that gained independence from Britain in 1962. Trinidad and Tobago is a multi-ethnic country comprising of East Indian 35.4\%, African descent 34.2\%, mixed and other ethnic groups 30.4\% (Central Statistical Office, 2020). The current study was conducted at the education faculty of a University in Trinidad and Tobago. At this university, prospective teachers are exposed to a four-year Bachelor of Education Degree Program consisting of a wide range of content, professional and pedagogical courses and the practicum.

A Student Health Survey conducted at the university under study in 2016 found that students were affected by high levels of anxiety (34\%), overwhelming anger (30\%), hopelessness $(26 \%)$ and thoughts of suicide (7\%) (Williams, 2016). In spite of these mental health problems the study found that $50 \%$ of the respondents did not seek help.

At this university, all registered students are eligible for counseling services at the student counseling services unit available at each campus. These services are free and confidential. Students can phone or drop in and schedule a time to speak with a Student Counselor for themselves. Alternatively, a friend or member of staff may encourage a student to visit the Student Counseling unit and assist him/her in making an initial appointment. While the Counselors usually see students by appointment, every effort is made to accommodate someone in an emergency.

\subsection{Definition of Key Term(s)}

Psychological Help-Seeking:

Any attempt to seek help for mental health problems provided by a professional counselor (e.g. psychologist, psychiatrist, counselor) (Seyfi, Poudel, Yasuoka \& Nanishi 2013).

\section{Literature Review}

This study is informed by two theoretical perspectives - the Health Belief Model and the Theory of Planned Behavior which provided a useful framework to better understand factors that might prevent students from seeking professional psychological help. The Health Belief Model (Becker, 1974; Henshaw \& Freedman-Doan, 2009) proposes four types of beliefs can influence a student to use the counseling services: perceived seriousness - students are more likely to seek help when they believe the problem can have serious consequences; perceived susceptibility - students' belief that they are vulnerable to at-risk behavior such as suicide; perceived benefits students' beliefs that seeking help is effective and perceived barriers - students' beliefs that there are few barriers to seeking help. An early study by Janzand Becker (1984) reported that of all the constructs, perceived barriers are the most significant in influencing changes in attitudes and health behaviors.

Within this framework, a study by Czyz, Adam, Horwitz, Eisenberg, Kramer and King (2013) of barriers to professional help-seeking among at-risk college students found that the most commonly cited barriers were treatment is not needed (60\%), lack of time (26.8\%) and preference for self-management (18\%).Other barriers that make it difficult for students to seek help from the counseling services on campus are attitudes, stigma, cultural beliefs, denial, and lack of knowledge about mental illness (Britt, Greene-Shortridge, Brink, Nguyen, \& Rath, 2008; Eisenberg et al., 2012; Eisenberg et al., 2011; Vanheusden et. Al., 2008). 
Stigma which is associated with mental illness and disorders has been identified as a major deterrent to seeking psychological help (Salaheddin \& Mason, 2016; Reichert, 2012).Individuals who seek psychological help are often viewed as weak, incompetent and having a lack of self-control and unable to take care of themselves (Corrigan, Edwards, Green, Diwan \& Penn, 2001;Read \& Law, 1999). Stigma and negative perceptions surrounding mental illness and treatment exert a strong influence on students' decision to seek psychological help (Corrigan, Druss \& Perlick, 2014; Eisenberg, Gollust, Golberstein \& Hefner, 2007).

A general mistrust of mental health services has also been associated with students' reluctance to seek professional counseling (Campbell \& McLean, 2002). These cultural values, which are transmitted from one generation to the other through socialization practices, influence the attitudes of Caribbean people towards seeking professional counseling. Students tend to reach out to their friends and family for support rather than seek out formal services (Nordberg, Hayes, McAleavey, Castonguay \& Locke, 2013).

The Theory of Planned Behaviour (Ajzen, 1991; Armitage \& Conner, 2001) has been used by numerous studies to predict and understand students' intentions to seek psychological help. This theory posits that students' intentions to seek help is influenced by three kinds of considerations: beliefs about the likely consequences of behaviour (behavioural beliefs), social pressures students feel when seeking help (normative beliefs) and beliefs about factors that may hinder or facilitate help-seeking (control beliefs). The more favourable the attitude and subjective norm and the greater the perceived control, the stronger should be one's intention to seek psychological help.

Indeed, attitudinal barriers have been related in numerous studies to intentions to seek help and the actual use of counselling services (Gulliver, Griffith \& Christensen, 2010). Research studies (Bohon, Cotter, Kravitz, Phillip \& Hernandezy Garcia, 2016; Wijerathrage, 2016) which used the TPB conceptual framework found that positive attitudes towards seeking psychological help is associated with a greater willingness to use the counselling services.

Socio-demographic variables such as gender, age, ethnicity, culture have been associated with help-seeking. Studies have investigated how these characteristics influence and impact attitudes to help-seeking (Jagdeo, Cox, Stein \& Sareen, 2009; Seyfi et al., 2013; Chen, Romero \& Karver, 2016). Picco, Abdin, Chong, et al., (2016) found that age, ethnicity, marital status, education and income were significantly associated with attitudes toward seeking professional psychological help. With regard to age, Jagdeo et al., (2009) and Seyfi et al., (2013) found that younger students had more negative attitudes toward seeking psychological help.

Research studies in many countries have reported that women have more favorable attitudes toward seeking psychological help than men (Vidourek, King, Nabors \& Merianos, 2014; Seyfi et al., 2013; Nam et al., 2010). According to Lindinger (2015), men are less willing to seek counseling because of stigma and norms of masculinity which emphasize self-control and self- reliance.

\section{Research Questions}

1. What are the most important factors that influence students' willingness to seek psychological help?

2. Are there significant differences in perceived barriers to psychological help-seeking based on demographic characteristics (sex, year group, age, part-time/full-time status, residence (urban/rural) and ethnicity?

3. What is the relationship between different categories of psychological help-seeking?

4. What reasons do students give for not using psychological health services at the university?

\section{Methodology}

The study used a sequential explanatory mixed methods research design. The rationale for this approach is that the quantitative data and results provide a general picture of the research problem while the qualitative data and its analysis will refine and explain those statistical results by exploring participants' views in more depth (Figure $1)$. 


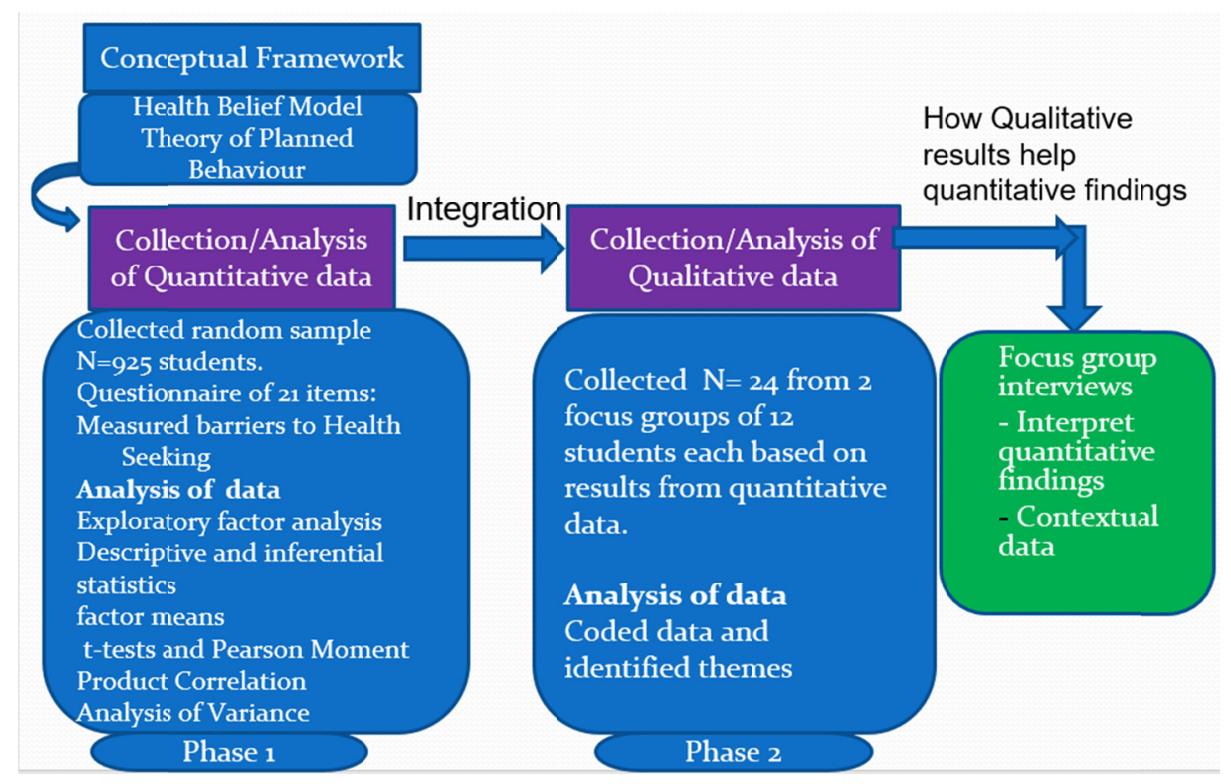

Figure 1. Conceptual framework

\subsection{Phase 1}

A questionnaire survey was used to measure barriers to seeking professional help from a random sample of 925 students. The questionnaire further sought to find out whether there were significant differences between perceived barriers to help-seeking based on sex, age, full-time/part-time status of students, place of residence (urban, rural) and ethnicity.

The sample comprised 131 (14.1\%) male and 794 (85.8\%) females; 571 (16.7\%) full-time and 354 (38.2\%) part-time students. Of the total students 438 (47.4\%) live in urban communities and 487 (52.6) live in rural communities. There were 331 (35.8\%) Year 1, 223 (24.1\%) Year 2, 169(18.3\%) Year 3 and 202 (21.8\%) Year 4 students. The ages of students ranged from less than 21 years (308), 21-25 years (330) and over 25 years (287). With regard to ethnicity, there were 527 (57\%) Indo-Trinidadians, 155 (16.8\%) Afro-Trinidadians, 229 (24.8\%) Mixed and 14 (1.5\%) from other minority groups. Responses of 'Other' were excluded because of the small sample. Table 1 shows the demographic characteristics of the respondents.

Table 1. Demographic characteristics

\begin{tabular}{ll}
\hline Demographic & $\mathrm{N}(\%)$ Students \\
\hline Year Groups & \\
\hline 1 & $331(35.8 \%)$ \\
\hline 2 & $223(24.1 \%)$ \\
\hline 3 & $169(18.3 \%)$ \\
\hline 4 & $202(21.8 \%)$ \\
\hline Total & $925(100 \%)$ \\
\hline Status & $354(38.2 \%)$ \\
\hline Part Time & $571(61.7 \%)$ \\
\hline Full Time & $925(100 \%)$ \\
\hline Total &
\end{tabular}




\begin{tabular}{|c|c|}
\hline \multicolumn{2}{|l|}{ Sex } \\
\hline Males & $131(14.1 \%)$ \\
\hline Females & $794(85.8 \%)$ \\
\hline Total & $925(100 \%)$ \\
\hline \multicolumn{2}{|l|}{ Age } \\
\hline$\leq 20$ & $308(33.3 \%)$ \\
\hline $21-25$ & $330(35.7 \%)$ \\
\hline$\geq 26$ & $287(31.0 \%)$ \\
\hline Total & $925(100 \%)$ \\
\hline \multicolumn{2}{|l|}{ Location } \\
\hline Rural & $487(52.6 \%)$ \\
\hline Urban & $438(47.4 \%)$ \\
\hline Total & $925(100 \%)$ \\
\hline \multicolumn{2}{|l|}{ Ethnicity } \\
\hline Indo-Trinidadian & $527(57 \%)$ \\
\hline Afro-Trinidadian & $155(16.8 \%)$ \\
\hline Mixed & $229(24.8 \%)$ \\
\hline Other & $14(1.5 \%)$ \\
\hline Total & $925(100 \%)$ \\
\hline
\end{tabular}

\subsubsection{Questionnaire}

The questionnaire was adapted from Topkaya, Salin \& Meydan (2017) study which sought to develop a scale (Barriers to Seeking Psychological Scale) to determine the barriers which influence psychological help-seeking in college students. Their findings found the scale to be a valid and reliable instrument. This scale consisted of 17 items that assessed students' perceptions of barriers to psychological help-seeking along five dimensions: fear of stigma (4 items), trust in the mental health professional (4 items), perceived devaluation ( 3 items), difficulty in self-disclosure (3 items), and lack of knowledge ( 3 items).

For the purposes of this study, another item was added to the Stigma subscale ("My family will disapprove if I seek psychological help") and a new dimension was included which was called Access to counseling services. The final instrument now consisted of 21 items and six sub-scales that reflected six (6) different types of barriers to psychological help-seeking (Appendix A). These sub-scales are: 1) Fear of stigma, which relate to the stigma or negative perceptions associated with seeking psychological help from the counselor. For example, "I worry that my friends will mock me if I seek help".

2) Trust reflected difficulties students have trusting mental health professionals. For example, "I worry that the counselor would not understand me".

3) Self-disclosure related to issues with regard to being emotionally open and sharing their problems with the counselor. For example, "I have difficulties sharing problems with a stranger".

4) Perceived devaluation reflected negative feelings about themselves when they receive psychological help. For example, "I would feel inadequate if I told my problems to the counsellor".

5) Lack of knowledge involved limited awareness or knowledge of available counseling services at the university. For example, "I don't know where such services are provided at the university". 
6) Accessibility involved difficulties students' experience to access counseling 1 services at the university. For example, "The counselor is not available when I need her" and "Hours for counseling services are not convenient for me".

The first section of the survey instrument gathered demographic data from participants (sex, age, year group, residence (urban or rural) and ethnicity. The second section consisted of 21 items related to 6 categories of barriers to help-seeking: stigma, trust, self-disclosure, perceived devaluation, lack of knowledge and access. Each item was rated on a 5-point Likert scale ranging from Strongly Disagree (1) to (5) Strongly Agree. Higher scores indicated higher perceived barriers in the related sub-scale.

\subsection{Phase 2}

Focus group interviews were conducted with students to explore in a more in-depth way reasons put forward in the survey for not seeking professional help. Qualitative data were collected through two focus groups. Each focus group consisted of 12 students. Potential participants who wished to participate in a focus group interview were asked to include their name and contact information on the questionnaire. Three students from each year group were then randomly selected from the volunteers. Focus groups interviews were recorded and then transcribed verbatim without identifying information. Transcripts were then coded manually.

\section{Analysis of Data and Findings}

Exploratory factor analysis was employed to determine the construct validity of items. Descriptive and inferential statistics were used to analyze the research questions. Statistical tests that were performed with the help of the Statistical Package for Social Scientists (SPSS-v-17) software were factor means, t-tests, Pearson Moment Product Correlation and Analysis of Variance.

\subsection{Findings: Exploratory Factor Analysis}

Students' responses to all 21 items were factor analyzed using principal component analysis with varimax rotation. The Kaiser-Meyer-Oklin (KMO) measure of sampling adequacy was 0.919 and the Bartlett's test of sphericity was significant $\left.\left(\mathrm{X}^{2}(210)=7324.49\right) \mathrm{p}<.05\right)$. It was therefore, appropriate to conduct exploratory factor analysis (Hair, Black, Babin \& Anderson, 2009).

Results of the factor analysis revealed four factors that explained $55.5 \%$ of the total variance (Table 2). The construction of the four factors were guided by the following criteria: a factor loading cut-off of 0.40 , eigen values greater than one rule and the reliability score of each factor. The four factors were supported by the scree plot which showed a 'levelling off' of Eigen values after four factors. The four factors are: Stigma (7 items), Privacy (4 items), Access (5 items) and Trust (5 items). The items in the categories Perceived devaluation and Lack of knowledge loaded on other factors. Two items in Perceived devaluation ("I feel inadequate if I told problems to the counsellor" and "Myself-confidence might decrease if I seek psychological help") loaded on Stigma (Factor 1). According to Corrigan (2004), stigma can include both social stigma (how the wider society views an individual who seeks psychological help and self-stigma (perceptions about oneself for seeking help). The third item ("I worry that psychological help will become habitual") loaded on Factor 4 (Trust) (Table 2). Also, one item ("Psychological help is too time consuming") in the category Lack of knowledge loaded on Factor 2 (Privacy/ Self-Disclosure) and two items ("Don't know how to contact professional providing help" and "No knowledge of psychological help at the university") loaded on Factor 3 (Access).

Cronbach alpha was computed to determine the internal consistency reliability of the items. The reliability of the four sub-scales ranged from .710 to .846 and the overall reliability of the survey instrument was .900 (Table 3).

Table 2. Loadings of the 4-Factorsolutionprincipalcomponent analysis result

\begin{tabular}{|c|c|c|c|c|c|c|c|}
\hline & & \multicolumn{6}{|c|}{ Factors } \\
\hline & & 1 & 2 & 3 & 4 & 5 & 6 \\
\hline Item & Factor 1 Stigma (7) & & & & & & \\
\hline 6 & Worry what other people will think & .783 & & & & & \\
\hline 9 & Worry friends will mock me. & .778 & & & & & \\
\hline 13 & My self-confidence might decrease. & .605 & & & & & \\
\hline 2 & Worry about being labeled 'problematic and/or crazy. & .551 & & & & & \\
\hline
\end{tabular}




\begin{tabular}{|c|c|c|c|c|c|c|c|}
\hline & & \multicolumn{6}{|c|}{ Factors } \\
\hline & & 1 & 2 & 3 & 4 & 5 & 6 \\
\hline 5 & Ashamed to tell problems to professional. & .548 & & & & & \\
\hline 14 & Psychological help not normal in my culture. & .517 & & & & & \\
\hline \multirow[t]{2}{*}{11} & Feel inadequate & .512 & & & & & \\
\hline & Factor 2 Privacy (4) & & & & & & \\
\hline 1 & Difficult to share problems with stranger. & & .730 & & & & \\
\hline 4 & Don't trust professional re confidentiality & & .724 & & & & \\
\hline 8 & Refuse to give information about private problems. & & .658 & & & & \\
\hline \multirow[t]{2}{*}{3} & Psychological help is too time consuming. & & .590 & & & & \\
\hline & Factor 3 Access (5) & & & & & & \\
\hline 20 & Hours for counseling not convenient. & & & .750 & & & \\
\hline 19 & Counselor not available in time of need. & & & .749 & & & \\
\hline 21 & Online access to counseling services not available & & & .712 & & & \\
\hline 10 & No knowledge of psychological help at university & & & .672 & & & \\
\hline \multirow[t]{2}{*}{7} & Don't know how to contact professional providing help. & & & .542 & & & \\
\hline & Factor 4 Trust (4) & & & & & & \\
\hline 17 & Worry about insensitive treatment. & & & & .767 & & \\
\hline 16 & Worry about being listened to adequately. & & & & .757 & & \\
\hline 15 & Worry that psychological help will become habitual. & & & & .642 & & \\
\hline 12 & Worry that professional would not understand me. & & & & .544 & & \\
\hline \multirow[t]{2}{*}{18} & Worry that family may not approve. & & & & .469 & & \\
\hline & & 7.177 & 2.113 & 1.313 & 1.063 & & \\
\hline \multicolumn{8}{|c|}{ Eigenvalue } \\
\hline \multicolumn{2}{|c|}{ Variance } & 34.1 & 10.1 & 6.25 & 5.06 & & \\
\hline
\end{tabular}

Table 3. Reliability statistics

\begin{tabular}{lll}
\hline Factor & Items & Cronbach Alpha \\
\hline Stigma & 7 & .846 \\
\hline Privacy & 4 & .710 \\
\hline Access & 5 & .762 \\
\hline Trust & 5 & .820 \\
\hline Overall & 21 & .900 \\
\hline
\end{tabular}

5.2 Research Question 1: What Are the Most Important Factors That Influence Students' Willingness to Seek Psychological Help?

This research question used descriptive statistics to find out which of the factors had the most influence on students' attitudes towards help-seeking. The means and standard deviations were used for comparison. Of the four factors, students were affected most by issues related to privacy/self-disclosure $(M=2.97)$. This was followed by concerns of access/availability of counseling services $(M=2.78)$, trust issues $(M=2.68)$ and stigma $(\mathrm{M}=2.43)$.Stigma was perceived as the least important factor to influence seeking help from the counseling services (Table 4). 
Table 4. Attitudes towards psychological help-seeking factors: scale mean, $\mathrm{n}$ and standard deviation

\begin{tabular}{llll}
\hline Factors & $\mathrm{N}$ & Mean & SD \\
\hline Stigma & 925 & 2.43 & .815 \\
\hline Privacy & 925 & 2.97 & .897 \\
\hline Access & 925 & 2.78 & .770 \\
\hline Trust & 925 & 2.68 & .893 \\
\hline
\end{tabular}

5.3 Research Question 2: Are There Significant Differences in Perceived Barriers to Psychological Help-Seeking Based on a) Sex b) Residence (Urban and Rural) c) Part-Time/Full-Time Status e) Year Group (Year 1 to 4) and Age?

2(a) Differences based on Sex

The results of t-tests showed a significant difference between male and female students' attitudes to help-seeking on Factor 4-Trust. Female students had more negative attitudes with regard to concerns related to trust (Table 5).

Table 5. T-tests results comparing male and female students' perceptions

\begin{tabular}{lllllll}
\hline Factor & Sex & N & Mean & S.D. & t & Sig \\
\hline F1 & M & 131 & 2.36 & 0.807 & -1.09 & .277 \\
& F & 794 & 2.45 & 0.817 & & \\
\hline F2 & M & 131 & 2.88 & 0.941 & -1.10 & .271 \\
& F & 794 & 2.98 & 0.889 & & \\
\hline F3 & M & 131 & 2.76 & 0.857 & -.348 & .729 \\
& F & 794 & 2.78 & 0.755 & & \\
\hline F4 & M & 131 & 2.51 & 0.906 & -2.22 & $.028^{*}$ \\
& F & 794 & 2.70 & 0.888 & & \\
\hline
\end{tabular}

${ }^{*} \mathrm{p}<0.05$; Key: F1- Stigma; F2- Privacy, F3- Access, F4- Trust

2 (b) Residence (Urban and Rural)

There were no significant differences in students' attitudes to psychological help-seeking in urban and rural communities as shown in Table 6.

Table 6. T-test results comparing urban and rural students' attitudes

\begin{tabular}{lllllll}
\hline Factor & Status & $\mathrm{N}$ & Mean & S.D. & $\mathrm{t}$ & Sig \\
\hline F1 & $\mathrm{U}$ & 438 & 2.42 & 0.845 & -.479 & .632 \\
& $\mathrm{R}$ & 487 & 2.45 & 0.788 & & \\
\hline F2 & $\mathrm{U}$ & 438 & 2.96 & 0.883 & -.274 & .784 \\
& $\mathrm{R}$ & 487 & 2.97 & 0.909 & & \\
\hline F3 & $\mathrm{U}$ & 438 & 2.79 & 0.780 & .233 & .816 \\
& $\mathrm{R}$ & 487 & 2.78 & 0.762 & & \\
\hline F4 & $\mathrm{U}$ & 438 & 2.67 & 0.907 & -.180 & .857 \\
& $\mathrm{R}$ & 487 & 2.68 & 0.881 & & \\
\hline
\end{tabular}

${ }^{*} \mathrm{p}<0.05$; Key: F1- Stigma; F2- Privacy, F3- Access, F4- Trust 
2(c) Differences based on full time and part time status

The T-tests results (Table 7) revealed that there was a significant difference in students' attitudes between Full-time $(\mathrm{M}=3.06)$ and Part-time $(\mathrm{M}=2.82)$ students with regard to privacy issues. There was also a significant difference on Factor 4-Trust between Full Time $(\mathrm{M}=2.76)$ and Part Time $(\mathrm{M}=2.53)$ students. Full Time students had more negative views with regard to matters related to privacy and trust.

Table 7. T-test results: full-time and part-time students

\begin{tabular}{lllllll}
\hline Factor & Status & N & Mean & S.D. & t & Sig \\
\hline F1 & P & 571 & 2.46 & 0.801 & 1.16 & .246 \\
& F & 354 & 2.39 & 0.837 & & \\
\hline F2 & P & 571 & 3.06 & 0.868 & 3.89 & $.000^{*}$ \\
& F & 354 & 2.82 & 0.924 & & \\
\hline F3 & P & 571 & 2.76 & 0.752 & -1.09 & .278 \\
& F & 354 & 2.82 & 0.798 & & \\
\hline F4 & P & 571 & 2.76 & 0.890 & 3.85 & $.000^{*}$ \\
& F & 354 & 2.53 & 0.879 & & \\
\hline
\end{tabular}

${ }^{*} \mathrm{p}<0.05$; Key: F1- Stigma; F2- Privacy, F3- Access, F4- Trust

\section{2 (d) Differences between year group}

The Analysis of Variance showed significant differences between the four year groups for Factor 4 - Trust (F (3, $921)=2.83, p=.037$ ) (Table 8). However, results of the Schaffer post hoc multiple comparison procedure indicated that the groups did not differ significantly. Comparison of the means for each year group showed that Year 4 students had more favorable attitudes with regard to trust issues $(\mathrm{M}=2.53)$ as compared to Year 1 $(\mathrm{M}=2.66)$, Year 2 (2.70) and Year 3 (2.75) students.

Table 8 . One way analysis of variance result for year groups

\begin{tabular}{|c|c|c|c|c|c|c|}
\hline & & SS & $\mathrm{df}$ & MS & $\mathrm{F}$ & $\mathrm{p}$ \\
\hline \multirow{3}{*}{ Stigma } & Between Groups & 3.27 & 3 & 1.09 & 1.64 & .178 \\
\hline & Within Groups & 611.0 & 921 & .687 & & \\
\hline & Total & 614.3 & 924 & & & \\
\hline \multirow{3}{*}{ Privacy } & Between Groups & .388 & 3 & .129 & .160 & .923 \\
\hline & Within Groups & 742.5 & 921 & .444 & & \\
\hline & Total & 742.9 & 924 & & & \\
\hline \multirow{3}{*}{ Access } & Between Groups & 3.27 & 3 & 1.09 & 1.84 & .137 \\
\hline & Within Groups & 544.6 & 921 & .520 & & \\
\hline & Total & 547.9 & 924 & & & \\
\hline \multirow{3}{*}{ Trust } & Between Groups & 6.73 & 3 & 2.24 & 2.83 & $.037 *$ \\
\hline & Within Groups & 729.7 & 921 & .426 & & \\
\hline & Total & 736.5 & 924 & & & \\
\hline
\end{tabular}

${ }^{*} \mathrm{p}<0.05$; Key: F1- Stigma; F2- Privacy, F3- Access, F4- Trust 
Table 9 . Scale means \& standard deviation by year groups

\begin{tabular}{lllll}
\hline Factors & Group & $\mathrm{N}$ & $\mathrm{M}$ & $\mathrm{SD}$ \\
\hline Stigma & 1 & 331 & 2.41 & .768 \\
\hline & 2 & 223 & 2.49 & .791 \\
\hline Privacy & 3 & 169 & 2.50 & .832 \\
\hline & 4 & 202 & 2.34 & .894 \\
\hline & 1 & 331 & 2.94 & .851 \\
\hline Access & 2 & 223 & 2.99 & .924 \\
\hline & 3 & 169 & 2.98 & .866 \\
\hline & 4 & 202 & 2.97 & .968 \\
\hline Trust & 1 & 331 & 2.78 & .769 \\
\hline & 2 & 223 & 2.71 & .730 \\
\hline & 3 & 169 & 2.89 & .790 \\
\hline & 4 & 202 & 2.78 & .794 \\
\hline
\end{tabular}

\section{2 (g) Differences between age groups}

Results of the analysis of variance indicated significant differences according to age groups for Privacy (F (2, $922)=9.76, \mathrm{p}=.000)$ and Trust $(\mathrm{F}=(2,922)=14.6, \mathrm{p}=.000)($ Table 10$)$.

The Schaffer post hoc multiple comparison procedure revealed that younger students $(<21$ years $)$ had more negative views $(\mathrm{M}=3.12)$ with regard to privacy issues when compared to older students $(21-25$ years $)(\mathrm{M}=$ $2.96)$ and $(>25)$ students $(\mathrm{M}=2.80)$. Also, students who were 21 years and younger had less trust in counseling services when compared to older students $(21-25$ years $)(\mathrm{M}=2.71)$ and students who were over 25 years $(\mathrm{M}=2.46)$ (Table 11).

Table 10. One way analysis of variance result for age groups

\begin{tabular}{|c|c|c|c|c|c|c|}
\hline & & SS & df & MS & $\mathrm{F}$ & $\mathrm{p}$ \\
\hline \multirow{3}{*}{ Stigma } & Between Groups & 2.12 & 2 & 1.06 & 1.60 & .203 \\
\hline & Within Groups & 612.2 & 922 & .664 & & \\
\hline & Total & 614.3 & 924 & & & \\
\hline \multirow{3}{*}{ Privacy } & Between Groups & 15.4 & 2 & 7.71 & 9.76 & $.000^{*}$ \\
\hline & Within Groups & 727.5 & 922 & .789 & & \\
\hline & Total & 742.9 & 924 & & & \\
\hline \multirow{3}{*}{ Access } & Between Groups & 1.45 & 2 & .724 & 1.22 & .295 \\
\hline & Within Groups & 546.5 & 922 & .593 & & \\
\hline & Total & 547.9 & 924 & & & \\
\hline \multirow{3}{*}{ Trust } & Between Groups & 22.7 & 2 & 11.3 & 14.6 & $.000^{*}$ \\
\hline & Within Groups & 713.8 & 922 & .774 & & \\
\hline & Total & 736.5 & 924 & & & \\
\hline
\end{tabular}

${ }^{*} \mathrm{p}<0.05$; Key: F1- Stigma; F2- Privacy, F3- Access, F4- Trust 
Table 11. Scale means\& standard deviation by age group

\begin{tabular}{lllll}
\hline Factors & Group & $\mathrm{N}$ & $\mathrm{M}$ & $\mathrm{SD}$ \\
\hline Stigma & $\leq 20$ & 308 & 2.48 & .734 \\
\hline & $21-25$ & 330 & 2.44 & .842 \\
\hline Privacy & $\geq 26$ & 287 & 2.37 & .864 \\
\hline & $\leq 20$ & 308 & 3.12 & .829 \\
\hline Access & $21-25$ & 330 & 2.96 & .914 \\
\hline & $\geq 26$ & 287 & 2.80 & .919 \\
\hline Trust & $\leq 20$ & 308 & 2.73 & .725 \\
\hline & $21-25$ & 330 & 2.82 & .793 \\
\hline & $\geq 26$ & 287 & 2.79 & .789 \\
\hline & $\leq 20$ & 308 & 2.84 & .888 \\
\hline
\end{tabular}

${ }^{*} \mathrm{p}<0.05$; Key: F1- Stigma; F2- Privacy, F3- Access, F4- Trust

2 (h) Differences based on ethnicity

The Analysis of Variance showed a significant difference based on ethnicity for Factor 1 - Stigma $(F(3,921)=$ $3.25, \mathrm{p}=.021)$ (Table 12). The Scheffe post hoc multiple comparison reported a significant difference between Afro-Trinidadian $(\mathrm{M}=2.28, \mathrm{SD}=.811)$ and Indo-Trinidadian students $(\mathrm{M}=2.50, \mathrm{SD}=.801)$ (Table 13). Indo -Trinidadian students had more negative attitudes with regard to stigma attached to psychological help-seeking.

Table 12. One way analysis of variance result for ethnicity

\begin{tabular}{|c|c|c|c|c|c|c|}
\hline & & $\mathrm{SS}$ & $\mathrm{df}$ & MS & $\mathrm{F}$ & $\mathrm{p}$ \\
\hline & Between Groups & 6.43 & 3 & 2.15 & 3.25 & $.021 *$ \\
\hline \multirow[t]{3}{*}{ Stigma } & Within Groups & 607.9 & 921 & .661 & & \\
\hline & Total & 614.3 & 924 & & & \\
\hline & Between Groups & 3.52 & 3 & 1.17 & 1.46 & .224 \\
\hline \multirow[t]{3}{*}{ Privacy } & Within Groups & 739.4 & 921 & .803 & & \\
\hline & Total & 742.9 & 924 & & & \\
\hline & Between Groups & 1.14 & 2 & .379 & .639 & .590 \\
\hline \multirow[t]{3}{*}{ Access } & Within Groups & 546.8 & 921 & .594 & & \\
\hline & Total & 547.9 & 924 & & & \\
\hline & Between Groups & 3.87 & 3 & 1.29 & 1.62 & .182 \\
\hline \multirow[t]{2}{*}{ Trust } & Within Groups & 732.6 & 921 & .795 & & \\
\hline & Total & 736.5 & 924 & & & \\
\hline
\end{tabular}

${ }_{\mathrm{p}}<$ <0.05; Key: F1- Stigma; F2- Privacy, F3- Access, F4- Trust

Table 13. Scale means\& standard deviation by ethnicity

\begin{tabular}{lllll}
\hline Factors & Group & $\mathrm{N}$ & $\mathrm{M}$ & $\mathrm{SD}$ \\
\hline Stigma & Indo & 527 & 2.50 & .801 \\
\hline & Afro & 155 & 2.28 & .811 \\
\hline
\end{tabular}




\begin{tabular}{lllll}
\hline & Mixed & 229 & 2.40 & .839 \\
& Other & 14 & 2.27 & .807 \\
\hline Privacy & Indo & 527 & 2.93 & .880 \\
\hline & Afro & 155 & 2.93 & .905 \\
\hline Access & Mixed & 229 & 3.07 & .923 \\
& Other & 14 & 3.02 & .953 \\
\hline & Indo & 527 & 2.77 & .773 \\
\hline Trust & Afro & 155 & 2.73 & .726 \\
\hline & Mixed & 229 & 2.84 & .788 \\
\hline & Other & 14 & 2.80 & .849 \\
\hline & Indo & 527 & 2.70 & .876 \\
\hline & Afro & 155 & 2.54 & .903 \\
\hline & Mixed & 229 & 2.69 & .927 \\
\hline
\end{tabular}

${ }_{*} \mathrm{p}<0.05$; Key: F1- Stigma; F2- Privacy, F3- Access, F4- Trust

\subsection{Research Question 3: What Is the Relationship Between the Different Categories of Psychological} Help-Seeking?

The Pearson Product Moment Correlation was used to investigate the relationship between psychological help-seeking factors. Table 13 shows that help-seeking factors are positively correlated with each other. There was a strong positive relationship between stigma and trust $(\mathrm{r}=.665, \mathrm{p}<0.01)$, stigma and privacy $(\mathrm{r}=0.561$, $\mathrm{p}<0.01)$ and access and trust $(\mathrm{r}=.521, \mathrm{p}<0.01)$ (Ary, Jacobs, Razavieh $\&$ Sorensen, 2006). A moderate positive relationship was found between privacy and trust $(\mathrm{r}=.483, \mathrm{p}<0.01)$ and stigma and access $(\mathrm{r}=.380, \mathrm{p}<0.01)$. There was also a weak correlation between privacy and access $(\mathrm{r}=.23, \mathrm{p}<0.01)$ (Table 14).

Table 14. Pearson moment correlations: relationship among help-seeking factors

\begin{tabular}{lllll}
\hline Factors & Stigma & Privacy & Access & Trust \\
\hline Stigma & 1 & $.561^{* *}$ & $.380^{* *}$ & $.665^{* *}$ \\
& .000 & .000 & .000 \\
\hline Privacy & 1 & $.234^{* *}$ & $.483^{* *}$ \\
& & .000 & .000 \\
\hline Access & & 1 & $.521^{* *}$ \\
& & & .000 \\
\hline Trust & & & 1 \\
\hline $\mathrm{p}<0.01(2$-tailed) & & &
\end{tabular}

5.5 Research Question 4: What Reasons Do Students Give for Not Using the Counseling Services at the University?

When questioned about the reasons for not using the psychological health services at the university, the following themes emerged. The majority of the students in the focus group interviews (18 out of 24) emphasized that issues of privacy/confidentiality were the main reasons for not using the mental/psychological services at the university.

"One of the things I am worried about is confidentiality. I am afraid that it can affect my career."

"The biggest problem for me is confidentiality." 
"Seeing the counselor at university may be an issue because I don't know if what I say will be confidential."

The issue of trust was also raised by more than two-thirds (17 out of 24) of the students in the focus group interviews. Students did not believe that their conversations with the counselor would remain anonymous. Prior experiences with counseling seem to have added to this mistrust of counselors. Some of the responses were:

"Trust is the biggest issue. At my high school guidance officer told all teachers about a student's problem which was a subject of discussion in the staffroom."

"I believe the counselor will discuss my problem with the lecturers and they will look at me differently"

"I don't feel safe sharing confidential problems with a complete stranger."

"I don't trust people with my problems."

The issue of stigma associated with mental illness was another reason given by more than half (15 out of 24) of the students in the focus group interviews for not using the mental/psychological services available at the university.

"Other students may notice me going for counseling and may treat me differently."

"Very concerned about what people may say or think when I walk into a counselor's office."

"Seeing the counselor at the university is an issue."

"If my peers see me visiting the counselor they would tend to judge my mental state."

The issue of access to the counseling services was reported by less than one half (10 out of 24) of the students. Students reported that their inability to access the services were another reason for not using the service.

"The fact that these services are not available online hinders me because of the class schedule."

"The counselor is not available when I get on campus."

"The few times I attempted to seek counseling the counselor was not there so I just never went back."

"Counseling services are not available to part time students."

In addition to the themes that support the findings of the survey, several other themes emerged in the focus group interviews. The issue of emotional openness was one of the main issues put forward by students (13 out of 24). Students suggested that they felt uncomfortable to speak to outsiders about issues that are personal or bring back bad memories.

"I do not feel comfortable speaking about my personal issues."

"Counseling delves into things that I rather forget; it brings back memories I want to forget."

"I do not like sharing my problems with someone I do not know."

"I am not a person to speak about my problems."

The lack of time was also mentioned by several students for their reason for not seeking mental/psychological services at the university. About two-thirds (16 out of 24) of the students indicated that limited time due to their busy schedules prevents them from not accessing the psychological services.

"Time is limited. I arrive at university just before class starts."

"Due to a busy schedule and workload it is difficult to seek psychological help."

"Due to the number of course we are required to do it would be too time consuming to seek counseling."

"Scheduling time to meet with the counselor is a bit difficult with classes and group meetings."

In addition to the above factors, several other factors were put forward by the participants. A small number ( 7 out of 24) of participants indicated that cultural beliefs and practices such as alternative remedies, religious beliefs, role of males in our society are also obstacles to accessing the mental/psychological services available at the university.

"I simply chose not to seek counseling because of my religion."

"Religious stigma- most people believe that God should be the one to help and not a counselor."

"Alternative remedies replace the need for psychological counseling."

"As a man you should not show any sign of weakness."

"Trinidad has a culture where males are supposed to handle all their problems." 
"Do not see the need to seek psychological counseling because it is not part of my personal beliefs."

"I can handle the problem and find a solution for myself."

"One should be strong enough to understand and face your problems."

The preference for using other sources of support was also mentioned by small number (4 out of 24) participants. These participants indicated that instead of accessing the services available at the university they prefer to speak to family members, ministers, friends or parents.

"I am a private person and prefer to talk to a friend or family member."

"I seek counseling from a Minister or pastor when needed."

"If I have a problem I usually discuss it with my friend or my parents."

"I usually discuss my problems with my husband and family members."

\subsection{Discussion}

Students rated issues related to privacy/self-disclosure followed by access to counseling services and trust concerns as affecting them the most. Findings from both quantitative and qualitative data suggest that students are apprehensive about seeking help as they are not comfortable sharing personal problems with a stranger. Underlying issues of trust are fears that personal information may not be kept confidential and the fear of negative repercussions. Students were critical of the lack of access to counseling services. Issues such as hours available for counseling, lack of awareness of counseling services, how to access counseling services and online access to services were factors that influenced help-seeking. These findings have been supported in the research literature. For example, a study by Salaheddin \& Mason (2016) reported major barriers to help-seeking were stigma, inability to express concerns, preference for self-reliance and difficulty accessing help. Interview data of college students (Kambouropoulos, 2015) revealed that the greatest barriers to help-seeking, were issues of confidentiality and 'invasion of privacy' and a preference for self-management. Indeed, discussing private and family matters with strangers is not viewed as acceptable behavior in Caribbean societies (Ali \& Toner, 2001; Marwaha \& Livingston, 2002). Counseling sessions require free emotional expression and disclosure of private information to a counselor/psychiatrist which is in conflict with values that emphasize self-reliance and self-silencing (Lin, 2002). Also, another possible reason may be students' lack of understanding of the counseling process and the role of the counselor and hence the lack of confidence that personal information will remain confidential.

However, findings on the relationship among the help-seeking factors showed a strong positive relationship between stigma surrounding psychological help-seeking and trust and privacy issues. According to Komiya, Good \& Sherrod (2000), students who are uncomfortable with expressing strong emotions might attribute their unwillingness to seek help to social stigma instead of attributing it to fear of emotions. They found a strong relationship between fear of emotions and stigma associated with psychological help.

As far as gender is concerned, female students had more negative attitudes with regard to trust. This finding is not consistent with numerous studies that suggest that males have less positive attitudes toward help-seeking and have more difficulties disclosing strong feelings in the counseling process. According to Ali and Toner (2001), in Caribbean culture women in particular silence certain thoughts and beliefs. A study of help-seeking among university students by Kearns, Muldoon, Msetfi \& Surgenor (2015) found that female students had a higher stigma toward help-seeking than males. It is possible also those female students sought more informal support from their friends and family (Goodwin, Behan, Kelly, McCarthy \& Hogan, 2016; Hill et al., 2011; Rose \& Rudolph, 2006). Goodwin et al. (2016) reported a greater prevalence of informal help-seeking behaviors than other types of help-seeking behavior among university students.

Findings also showed significant differences in attitudes toward help-seeking across age, year group, part-time/full-time students and ethnicity. Younger students $(<21)$ had significantly more negative attitudes than older students with regard to privacy and trust while students in the final year (Year 4) seemed to be more comfortable with seeking psychological help when compared to the other year groups. This is consistent with findings from several studies (Surgenor, 1985; Czyz et al., 2013). However, Picco et al. (2016) found that younger adults (18-34years) were more open to seeking professional psychological help. It is possible that younger students in this study prefer to self- manage or seek help from their friends. According to Coleman (1980), younger students are less trusting of professionals and mental health services and are less conforming. Ciarrochi, Wilson, Deane \& Rickwood (2003) found that younger students have more difficulties identifying and describing their emotions. Indeed, the first year is the point of greatest risk for students at the university. Students 
experience many challenges in the first year such as transition and coping with academic expectations and lack of skills required to cope at the university level. Therefore, urgent outreach programmers should target attitudes of first year students toward mental health and encourage use of the counseling services.

Full-time students also had more difficulties with regard to issues related to trust and privacy when compared to part-time students. Many part-time students tend to be older, more mature students while full-time students are primarily in the age range of 17- 24 and may seek help from their friends or other sources of informal help.

There were no significant differences in students' attitudes toward seeking psychological help with regard to residence in an urban or rural community. With regard to ethnicity, Indo-Trinidadians students were affected more by stigma associated with psychological help-seeking when compared with Afro-Trinidadians. Studies have found that cultural values, norms and beliefs greatly influence help-seeking behaviors (Loo \& Furnam, 2013; Nam, Chu, Lee, Kin \& Lee, 2010). In some cultures, seeking psychological help where one is required to disclose personal information to a stranger may be perceived as shameful. Indeed, given our multicultural society, further research is needed to explore the influence of cultural factors on perceptions of mental illness and help-seeking behaviors.

There was also a strong positive relationship between students' lack of knowledge of the counseling services and how to access help and lack of trust in the mental health professional. Interview data also found that many part-time students are not aware of counseling services and how to access psychological help and given their part-time status find the scheduled times for counseling services are inconvenient for them. Studies have reported that lack of information about how to access help and the lack of understanding of the psychological help process can prevent help-seeking (Topkaya, 2015; Czyz et al., 2013; Salim, 2010).

\subsection{Recommendations}

The following recommendations were made based on the findings of the study. The university should create outreach programs such as seminars and workshops to educate students about the issues and symptoms of mental health, the nature of counseling as well the benefits for students. In addition, success stories should be presented where possible which can help reduce stigma and can assure students that seeking psychological help is normal.

The university's counseling unit should be more visible and embark on a drive to promote counseling services through the use of advertisements via flyers and the CANVAS learning management system. Counselors also need to ensure all students are aware of the counseling services by visiting classes where possible and interacting with students. Students should also be informed of the location of the counselor's office and hours of counseling services. Additionally, counselors should seek to build trust among the students so that students feel comfortable with sharing personal information and assured of confidential nature of the psychological help process.

In an effort to reach more students and make the services more widely available the counseling unit should introduce online counseling services. A more proactive approach using technology should be implemented whereby students can interact with the counselor. For example, students should be able to email the counselor. A time delay for response to emails and an online office hours schedule should be posted. The counselor should also send prompts to students when he/she is online. This facility would facilitate students who are unable to come to the campus during the day and those who may be afraid to be seen accessing the services.

Finally, training should be given to all faculty members to recognize behavioral and emotional changes in their students. Faculty can then make referrals to the counselor. In addition, a mental health program focusing on self-care should be integrated into the teacher education programmer so that student teachers can identify and address problems with regard to their own mental health challenges and also support their colleagues and their friends.

\section{Conclusion}

Our study was limited to students at one university. Findings therefore, cannot be generalized to the wider population of students in Trinidad and Tobago. Further studies should be conducted to find out whether students at other higher education institutions experience similar barriers to accessing psychological help. The study was also limited to investigating four factors /barriers to psychological help-seeking in the first phase of the study. Future research should consider expanding the help - seeking scale to include other factors and further investigate the relationship between these factors and students' actual help-seeking behaviors. The study employed quantitative and qualitative data collection methods which provided a deeper insight into other key factors that prevented students from using the counseling services and identified specific areas that should be prioritized for intervention. Such factors were issues related to trust, confidentiality, lack of knowledge of counseling, stigma and accessibility of services. 
Future research should consider more qualitative approach /inquiry to provide more in-depth understanding of the influence of religion and ethnicity on students' attitudes to help -seeking.

Younger students were more reluctant to use the counseling services. Additional studies can explore further what are their sources of support and how do they go about seeking help for mental health problems and how effective are such sources of support.

Future research also need to evaluate the effectiveness of such interventions as outreach programs to educate students on mental illness and on online counseling which were recommended by students as a means of overcoming barriers of privacy/confidentiality, stigma and accessibility.

\section{References}

Acham, S. (2017, October). Minds Matter: Counseling Services Try to Help Campus Cope with Life. UWI Today. Retrieved from https://sta.uwi.edu/uwitoday/archive/october_2017/article23.asp

Ajzen, I. (1991). The theory of planned behavior. Organizational Behavior and Human Decision Processes, 50(2), 179-211. https://doi.org/10.1016/0749-5978(91)90020-T

Ali, A., \& Toner, B. B. (2001). Symptoms of depression among Caribbean women and Caribbean-Canadian women: An investigation of self-silencing and domains of meaning. Psychology of Women Quarterly, 25, 175-180.

Retrieved

from https://www.researchgate.net/publication/258181734_Symptoms_of_Depression_Among_Caribbean_Wom en_and_Caribbean-Canadian_Women_An_Investigation_of_Self-Silencing_and_Domains_of_Meaning

Armitage, C. J., \& Conner, M. A. (2001). Efficacy of the theory of planned behavior: a meta-analytic review. British Journal of Social Psychology, 40(4), 471-499. https://doi.org/10.1348/01446660116

Ary, D., Jacobs, L. C., Razavieh, A., \& Sorensen, C. (2006). Introduction to research in education (7th ed.). USA: Thompson Wadsworth.

Becker, M. H. (1974). The Health Belief Model and Personal Health Behavior. Health Education Monographs, 324-508. https://doi.org/10.1177/109019817400200407

Bohon, L. M., Cotter, K. A., Kravitz, R. L., Cello, P. C., \& Fernandez y Garcia, E. (2016). The Theory of Planned Behavior as it predicts potential intention to seek mental health services for depression among college students. Journal of American College Health, 1-10. https://doi.org/10.1080/07448481.2016.1207646

Britt, T. W., Greene-Shortridge, T. M., Brink, S., Nguyen, Q. B., Rath, J., Cox, A. L., ... Castro, C. A. (2008). Perceived stigma and barriers to care for psychological treatment: Implications for reactions to stressors in different contexts. Journal of Social and Clinical Psychology, 27(4), 317-335. https://doi.org/10.1521/jscp.2008.27.4.317

Campbell, C., \& McLean, C. (2002). Inter-ethnic comparisons in peoples' accounts of local community participation: The context of health inequalities in England. Journal of Community and Applied Social Psychology, 12(1), 13-30.

Central Statistical Office. (2020). Population and housing community register. Retrieved from https://cso.gov.tt/subjects/population-and-vital-statistics/population/

Chen, J. I., Romero, G. D., \& Karver, M. S. (2016). The relationship of perceived campus culture to mental health help-seeking intentions. Journal of Counseling Psychology, 63(6), 677-684. https://doi.org/10.1037/cou0000095

Ciarrochi, J., Wilson, C., Deane, F., \& Rickwood, D. (2003). Do Difficulties with Emotions Inhibit Help-seeking in Adolescence? The Role of Age and Emotional Competence in Predicting Help-seeking Intentions. Counselling Psychology Quarterly, 16(2), 103-120. https://doi.org/10.1080/0951507031000152632

Coleman, J. C. (1980). The nature of adolescence. New York: Methuen.

Corrigan, P. W., Druss, B. G., \& Perlick, D. A. (2014). The impact of mental illness stigma on seeking and participating in mental health care. Psychological Science in the Public Interest, 15(2), 37-70. https://doi.org/10.1177/1529100614531398

Corrigan, W., Edwards, B., Green, A., Diwan, L., \& Penn, L. (2001). Prejudice, social distance, and familiarity with mental illness. Schizophr Bull, 27(2), 219-225. https://doi.org/10.1093/oxfordjournals.schbul.a006868 
Czyz, E., Adam, M., Horwitz, B., Eisenberg, D., Kramer, A., \& King, C. (2013). Self-reported Barriers to Professional Help Seeking Among College Students at Elevated Risk for Suicide. Journal of American College Health, 61(7), 398-406. https://doi.org/10.1080/07448481.2013.820731

Eisenberg, D., Gollust, S., Golberstein, E., \& Hefner, J. (2007). Prevalence and correlates of depression, anxiety, and suicidality among university students. American Journal of Orthopsychiatry, 77(4), 534-542. https://doi.org/10.1037/0002-9432.77.4.534

Eisenberg, D., Hunt, J., Speer, J., \& Zivin, K. (2011). Mental Health Service Utilization Among College Students in the United States. The Journal of Nervous and Mental Disease, 199(5), 301-308. https://doi.org/10.1097/NMD.0b013e3182175123

Eisenberg, D., Speer, N., \& Hunt, J. B. (2012). Attitudes and beliefs about treatment among college students with untreated mental health problems. Psychiatric Services (Washington, D.C.), 63(7), 711-713. https://doi.org/10.1176/appi.ps.201100250

Goodwin, J., Behan, L., Kelly, P., McCarthy, K., \& Horgan, A. (2016). Help-seeking behaviors and mental well-being of first year undergraduate university students. Psychiatry Res, 246, 129-135. https://doi.org/10.1016/j.psychres.2016.09.015

Government of Trinidad and Tobago. (2018). Sixth report of the Joint Select Committee on social services and public administration on an inquiry into mental health and wellness services and facilities in Trinidad and Tobago. Retrieved from http://ttparliament.org/reports/p11-s4-J-20181120-SSPA-r6-MHTT.pdf

Gulliver, A., Griffiths, K., \& Christeensen, H. (2010). Perceived Barriers and Facilitators to Mental Health Help-Seeking in Young People: A Systematic Review. BMC Psychiatry, 10(113), 113. https://doi.org/10.1186/1471-244X-10-113

Hair, Jr. J. F., Black, W. C., Babin, B. J., \& Anderson, R. E. (2009). Multivariate data analysis (7th ed.). Prentice Hall, Upper Saddle River.

Henshaw, E. J., \& Freedman-Doan, C. R. (2009). Conceptualizing mental health care utilization using the health belief model. Clinical Psychology: Science and Practice, 16(4), 420-439. https://doi.org/10.1111/j.1468-2850.2009.01181.x

Hill, C., Satterwhite, D., Larrimore, M., Mann, A. V., Simon, R., Simpson, A., ... Knox, S. (2011). Attitudes about psychotherapy: A qualitative study of introductory psychology students who have never been in psychotherapy and the influence of attachment style. Counselling and Psychotherapy Research. https://doi.org/10.1080/14733145.2011.629732To

Jagdeo, A., Cox, B. J., Stein, M. B., \& Sareen, J. (2009). Negative attitudes toward help seeking for mental illness in 2 population-based surveys from the United States and Canada. The Canadian Journal of Psychiatry, 54(11), 757-766. https://doi.org/10.1177/070674370905401106

Janz, N. K., \& Becker, M. H. (1984). The Health Belief Model: A decade later. Health Education Quarterly, 11(1), 1-47. https://doi.org/10.1177/109019818401100101

Kambouropoulos, A. (2015). Barriers to the utilisation of counselling services by international students. World Journal of Education, 5(5). https://doi.org/10.5430/wje.v5n5p1

Kearns, M., Muldoon, O., Msetfi, R., \& Surgenor, P. (2015). Understanding help seeking in university students: the role of group identity, stigma and exposure to suicide and help seeking. Frontiers in Psychology. https://doi.org/10.3389/fpsyg.2015.01462

Lin, Y. (2002). Taiwanese university students' conceptions of counseling. Journal of Contemporary Psychothearpy, 31, 199-211.

Lindinger-Sterhart, S. (2015). Help-seeking behaviors of men for mental health and the impact of diverse cultural backgrounds. International Journal of Social Science Studies, 3(1), 1-6.

Loo, P. W., \& Furnham, A. (2013). Knowledge and beliefs about depression among urban and rural Indian Malaysians. Mental Health, Religion and Culture, 16, 1009-1029.

Marwaha, S., \& Livingston, G. (2002). Stigma, racism or choice. Why do depressed ethnic elders avoid $\begin{array}{lllll}\text { psychiatrists? } & \text { Journal of }\end{array}$ https://doi.org/10.1016/S0165-0327(01)00470-0 
Muldoon, O., Msetfi, R., \& Surgenor, P. (2015). Understanding help seeking in university students: the role of group identity, stigma and exposure to suicide and help seeking. Frontiers in Psychology, 6. https://doi.org/10.3389/fpsyg.2015.01462

Nam, S. K., Chu, H. J., Lee, M. K., Lee, J. H., Kim, N., \& Lee, S. M. (2010). A meta-analysis of gender differences in attitudes toward seeking professional psychological help. Journal American College of Health, 59, 110-116.

National Alliance on Mental Illness. (2014). Treatment and services. Retrieved from $\mathrm{http} / / /$ www.nami.org/template.cfm?section=About_Treatments_and-Supports

Nordberg, S. S., Hayes, J. A., McAleavey, A. A., Castonguay, L. G., \& Locke, B. D. (2013). Treatment utilization on college campuses: Who seeks help for what?. Journal of College Counseling, 16(3), 258-274. https://doi.org/10.1002/j.2161-1882.2013.00041.x

Oswalt, S., Lederer, A., Chestnut-Steich, K., Day, C., Halbritter, A., \& Ortiz, D. (2020). Trends in college students' mental health diagnoses and utilization of services, 2009-2015. Journal of American College Health, 68(1), 41-51. https://doi.org/10.1080/07448481.2018.1515748

Picco, L., Abdin, E., Chong, S. A., Pang, S., Shafie, S., Chua, B. Y., ... Subramaniam, M. (2016). Attitudes toward seeking professional psychological help: factor structure and socio-demographic predictors. Frontiers in Psychology, 7, 547. https://doi.org/10.3389/fpsyg.2016.00547

Read, J., \& Law, A. (1999). The relationship of causal beliefs and contact with users of mental health services to attitudes to the "mentally ill". International Journal of Social Psychiatry, 45, 216-229. https://doi.org/10.1177/002076409904500309

Reichert, E. (2012). Reducing stigma barriers to help-seeking behaviors among college students. Psychology, 3(10), 892. https://doi.org/10.4236/psych.2012.310134

Rose, A. J., \& Rudolph, K. D. (2006). A review of sex differences in peer relationship processes: Potential trade-offs for the emotional and behavioral development of girls and boys. Psychological Bulletin, 132(1), 98-131. https://doi.org/10.1037/0033-2909.132.1.98

Salaheddin, K., \& Mason, B. (2016). Identifying barriers to mental health help-seeking among young adults in the UK: a cross-sectional survey. The British Journal of General Practice, 66(651), e686-e692. https://doi.org/10.3399/bjgp16X687313

Seemungal, T. (2018). Support, not skepticism, for those with mental illness. UWI Today. Retrieved from https://sta.uwi.edu/uwiToday/pdfs/UWItodayfebruary2019.pdf

Seyfi, F., Poudel, K. C., Yasuoka, J., \& Nanishi, K. (2013). Intention to seek professional psychological help among college students in Turkey: influence of help-seeking attitudes. BMC Res Notes, 6, 519. https://doi.org/10.1186/1756-0500-6-519

Surgenor, L. J. (1985). Attitudes toward seeking professional psychological help. New Zealand Journal of Psychology, 14(1), 27-33.

Topkaya, N., Salin, E., \& Meydan, B. (2017). The development, validity and reliability of the barriers to seeking psychological help scale for college students. International Journal of Higher Education, 6(1), 48-62. https://doi.org/10.5430/ijhe.6n1p48

Vanheusden, K., Cornelis, M., Van Der Ende, J., Van Lenthe, F., Mackenbach, J., \& Verhulst, F. (2008). Young adults face major barriers to seeking help from mental health services. Patient Education and Counseling, 73(1), 97-104. Retrieved from https://www.ncbi.nlm.nih.gov/pubmed/18584997

Vanheusden, K., Mulder, C. L., Van der Ende, J., Van Lenthe, F., Mackenbach, J. P., \& Verhulst, F. C. (2008). Young adults face major barriers to seeking help from mental health services. Patient Education \& Counseling, 73, 97-104. https://doi.org/10.1016/j.pec.2008.05.006

Vidourek, R., King, K., Nabors, L., \& Merianos, A. (2014). Students benefits and barriers to mental health help-seeking. Health Psychology and Behavioral Medicine, 2(1). https://doi.org/1009-022

Von Ah, D., Ebert, S., Ngamvitroj, A., Park, N., \& Kang, D. (2004). Predictors of Health Behaviours in College Students. Journal of Advanced Nursing. Retrieved from https://www.ncbi.nlm.nih.gov/pubmed/15533084

Williams, L. (2016). Student Retention and Success at the University of Trinidad and Tobago (pp. 1-39). Student Support Services of the University of Trinidad and Tobago. Retrieved from 
https:/utt.edu.tt/accreditation/2017/R-077\%20Presentation $\% 20$ Retention $\% 20$ and $\% 20$ Student $\% 20$ Success $\%$ 20Paper\%20for\%20AC.pdf

\section{Appendix}

Appendix A. Items and Subscales of Psychological Help-Seeking Survey

\begin{tabular}{|c|c|c|}
\hline Sub Scales & No & Item \\
\hline \multirow{5}{*}{ Stigma } & 2 & Worry about being stigmatized as 'problematic' and or 'crazy' \\
\hline & 6 & Worry what other people would think about me \\
\hline & 9 & Worry about whether friends would mock me \\
\hline & 14 & Not accepted as 'normal/natural' in the culture in which I grew up \\
\hline & 18. & Worry that family may not approve \\
\hline \multirow{4}{*}{ Trust } & 4 & Don't trust professionals to keep issues confidential \\
\hline & 12 & Worry that counsellor would not understand me \\
\hline & 16 & Worry whether counsellor would listen to me adequately \\
\hline & 17 & Worry that counsellor would be insensitive to my problems \\
\hline \multirow{3}{*}{ Self-disclosure } & 1 & Have difficulty sharing problems with a stranger \\
\hline & 5 & Feel ashamed to tell problems to counselor \\
\hline & 8 & $\begin{array}{l}\text { Refuse to give information about my private problems even to a } \\
\text { professional }\end{array}$ \\
\hline \multirow{3}{*}{ Perceived devaluation } & 11 & Feel inadequate if I told my problems to the counselor \\
\hline & 13 & My self-confidence might decrease if I seek psychological help \\
\hline & 15 & $\begin{array}{l}\text { Worry that if I take psychological help, I would need it whenever I have } \\
\text { a problem }\end{array}$ \\
\hline \multirow{3}{*}{ Lack of knowledge } & 3 & Don't want to spend time seeking counseling as it would take too long \\
\hline & 7 & Don't know how to contact counselor \\
\hline & 10 & Don't know where counseling services are provided at the university \\
\hline \multirow{3}{*}{ Access } & 19 & Counselor is not available when I need her \\
\hline & 20 & Hours for counseling services are not convenient for me \\
\hline & 21 & Online access to counseling services are not available \\
\hline
\end{tabular}

\section{Copyrights}

Copyright for this article is retained by the author(s), with first publication rights granted to the journal.

This is an open-access article distributed under the terms and conditions of the Creative Commons Attribution license (http://creativecommons.org/licenses/by/4.0/). 